\title{
Leukotrienes modulate secretion of progesterone and prostaglandins during the estrous cycle and early pregnancy in cattle: an in vivo study
}

\author{
Anna J Korzekwa, Mamadou M Bah, Andrzej Kurzynowski, Karolina Lukasik, \\ Agnieszka Groblewska and Dariusz J Skarzynski
}

Department of Reproductive Immunology and Pathology, Institute of Animal Reproduction and Food Research, Polish Academy of Sciences, 10-747 Olsztyn, Poland

Correspondence should be addressed to A J Korzekwa; Email: a.korzekwa@pan.olsztyn.pl

\begin{abstract}
Recently, we showed that leukotrienes (LTs) regulate ovarian cell function in vitro. The aim of this study was to examine the role of LTs in corpus luteum $(C L)$ function during both the estrous cycle and early pregnancy in vivo. mRNA expression of LT receptors (BLT for LTB 4 and $C Y S L T$ for $\left.\mathrm{LTC}_{4}\right)$, and 5-lipoxygenase (5-LO) in $\mathrm{CL}$ tissue and their localization in the ovary were studied during the estrous cycle and early pregnancy. Moreover, concentrations of LTs $\left(\mathrm{LTB}_{4}\right.$ and $\left.\mathrm{C}_{4}\right)$ in the CL tissue and blood were measured. 5-LO and BLT mRNA expression increased on days 16-18 of the cycle, whereas CYSLT mRNA expression increased on days 16-18 of the pregnancy. The level of $\mathrm{LTB}_{4}$ was evaluated during pregnancy compared with the level of $\mathrm{LTC}_{4}$, which increased during CL regression. LT antagonists influenced the duration of the estrous cycle: the $\mathrm{LTC}_{4}$ antagonist (azelastine) prolonged the luteal phase, whereas the $\mathrm{LTB}_{4}$ antagonist (dapsone) caused earlier luteolysis in vivo. Dapsone decreased progesterone $\left(\mathbf{P}_{4}\right)$ secretion and azelastine increased $\mathbf{P}_{4}$ secretion during the estrous cycle. In summary, LT action in the bovine reproductive tract is dependent on LT type: LTB $_{4}$ is luteotropic during the estrous cycle and supports early pregnancy, whereas $\mathrm{LTC}_{4}$ is luteolytic, regarded as undesirable in early pregnancy. LTs are produced/secreted in the CL tissue, influence prostaglandin function, and serve as important factors during the estrous cycle and early pregnancy in cattle.

Reproduction (2010) 140 767-776
\end{abstract}

\section{Introduction}

The corpus luteum $(\mathrm{CL})$ is the principal source of progesterone $\left(\mathrm{P}_{4}\right)$ in mammals. $\mathrm{P}_{4}$ supports the secretory functions of the endometrium, which sustain early embryonic development, implantation, and placentation (Niswender et al. 2000). In cows, the main signal for pregnancy recognition and $\mathrm{CL}$ maintenance is interferon $\tau$ (IFNT; Thatcher et al. 2001, Spencer et al. 2007, Bazer et al. 2008). Nevertheless, the bovine conceptus produces numerous signals during early pregnancy including steroids, prostaglandins (PGs), and other proteins (Lewis et al. 1982, Eley et al. 1983, Thatcher et al. 1984). Uterine and ovarian PGs are considered to be important factors for regulating reproductive events such as ovulation, luteolysis, embryo implantation, and maintaining pregnancy (Weems et al. 2006). Generally, $\mathrm{PGE}_{2}$ acts in luteotropic and luteoprotective ways, which leads to lengthening of the lifespan of the $C L$ and $P_{4}$ production (Weems et al. 1997, Kotwica et al. 2003), whereas $\mathrm{PGF}_{2 \alpha}$ is the main luteolytic agent in ruminants (McCracken et al. 1999). Thus, in signaling from the conceptus to the maternal system for maternal recognition of pregnancy, the correct contact between IFNT and all ovarian and uterine factors, such as $\mathrm{P}_{4}$ and PGs, plays a pivotal role (Arosh et al. 2004, Weems et al. 2006). In this study, we examine the action of leukotrienes (LTs) as another potential trigger of reproductive processes in cattle.

LTs are synthesized by 5-lipoxygenase (5-LO) and are commonly known as potential inflammatory factors that cause edema in respiratory tract diseases, but they also have roles in reproduction and may enhance the action of PGs (Samuelsson 2000). Receptors for LTs are classified into two separate groups with respect to structure and cell location: BLT for $\mathrm{LTB}_{4}$ and CYSLT for cysteinyl LTs ( $\mathrm{LTC}_{4}, \mathrm{LTD}_{4}$, and $\mathrm{LTE}_{4}$; Izumi et al. 2002). In humans, there are two isoforms of receptor for $\mathrm{LTB}_{4}$ (LTB4R and LTB4R2, also known as BLT1 and BLT2; Tager \& Luster 2003) and at least two receptors for cysteinyl LTs (CYSLTR1 and CYSLTR2; Jones \& Rodger 1999), whereas there are no data about the protein expression/localization of LT receptors in the bovine reproductive tract. LTs play a role in the bovine reproductive tract: intraluteal infusion of $\mathrm{PGF}_{2 \alpha}$ by a microdialysis system on day 12 of the estrous cycle was 
shown to increase the levels of both $\mathrm{LTB}_{4}$ and $\mathrm{C}_{4}$ in $\mathrm{CL}$ perfusate (Blair et al. 1997). The secretory functions of bovine CL cells were shown to be regulated not only by PGs but also by LTs (Milvae et al. 1986, Korzekwa et al. $2010 a, 2010 b)$. We recently showed that mRNA for 5-LO and LT receptors is expressed in ovarian cell types, including steroidogenic and endothelial $\mathrm{CL}$ cells and granulosa cells (Korzekwa et al. 2010b). LTs are found to be auto/paracrine factors modulating the secretory functions of ovarian cells depending on the stage of the cycle and type of $\mathrm{LT}$. $\mathrm{LTB}_{4}$ seems to play a luteotropic role in the $\mathrm{CL}$, stimulating $\mathrm{P}_{4}$ and $\mathrm{PGE}_{2}$ secretions, whereas $\mathrm{LTC}_{4}$ stimulates the secretion of luteolytic $\mathrm{PGF}_{2 \alpha}$ and may enhance the luteolytic cascade within the bovine CL steroidogenic cells (Korzekwa et al. 2010a). These in vitro results need to be supported by in vivo studies to help us understand the complete effects of LT action on the bovine reproductive tract during the estrous cycle. Moreover, there is a lack of knowledge about the role of LTs in early pregnancy.

The main goal of this study was to determine and compare the actions of endogenous LTs at the end of luteal phase of the estrous cycle and during early pregnancy in cattle. We monitored the concentrations of selected LTs, $B_{4}$ and $C_{4}$, in the plasma and $C L$ tissue and we evaluated their production and expression in the $\mathrm{CL}$ tissue during the estrous cycle compared with early pregnancy. Furthermore, we examined the influence of endogenous LTs on the CL lifespan and function, as well as secretory function in the reproductive tract on day 16 of cycle/pregnancy by measuring $\mathrm{P}_{4}$ and $\mathrm{PG}\left(\mathrm{PGE}_{2}\right.$ and PGFM) concentrations in the blood samples after infusion of selective antagonists of $\mathrm{LTB}_{4}$ and $\mathrm{C}_{4}$ into the aorta abdominalis.

\section{Results}

Experiment 1: LT mRNA expression and production in the bovine $C L$ tissue and its localization in the ovary during the estrous cycle and in early pregnancy

Figure 1 shows mRNA expression for LTRs (BLT and CYSLT) and 5-LO in the $\mathrm{CL}$ tissue during the estrous cycle and early pregnancy. BLT mRNA expression was upregulated on days $16-18$ of pregnancy $(P<0.05)$, whereas CYSLT mRNA expression was higher on days 8-10 and $16-18$ of the estrous cycle $(P<0.05)$. 5-LO mRNA expression was upregulated on days 16-18 of pregnancy $(P<0.05)$.

Light microscopic observations for immunohistochemical staining of BLT and CYSLT and 5-LO localization in ovarian tissue on days 8-10 of the estrous cycle as a representative period are shown in Fig. 2. BLT and CYSLT and 5-LO were not only present in theca and stromal cells and in the area of preantral follicles but also in epithelial cells, smooth muscle cells of ovarian aortas, and in steroidogenic luteal cells of the CL.
$\mathrm{LTB}_{4}$ concentration remained unchanged throughout the cycle (days $2-4,8-10$, and $16-18, P>0.05$; Fig. 3 ) but increased on days $8-10$ and $16-18$ of pregnancy $(P<0.05)$. LTC $_{4}$ concentration was higher on days $16-18$ of the cycle and lower on days 8-10 and 16-18 of pregnancy $(P<0.05)$.

\section{Experiment 2: $\mathrm{LTB}_{4}$ and $\mathrm{C}_{4}$ concentrations in the blood during the estrous cycle and early pregnancy}

Figure 4 shows $\mathrm{LTB}_{4}$ and $\mathrm{C}_{4}$ concentrations during the estrous cycle and early pregnancy in blood collected from jugular vein on days $0,2,8,10,15,16,17$, and 21 .

During the cycle, the level of LTC $_{4}$ increased between days 15 and 17 of the estrous cycle $(P<0.05)$, whereas
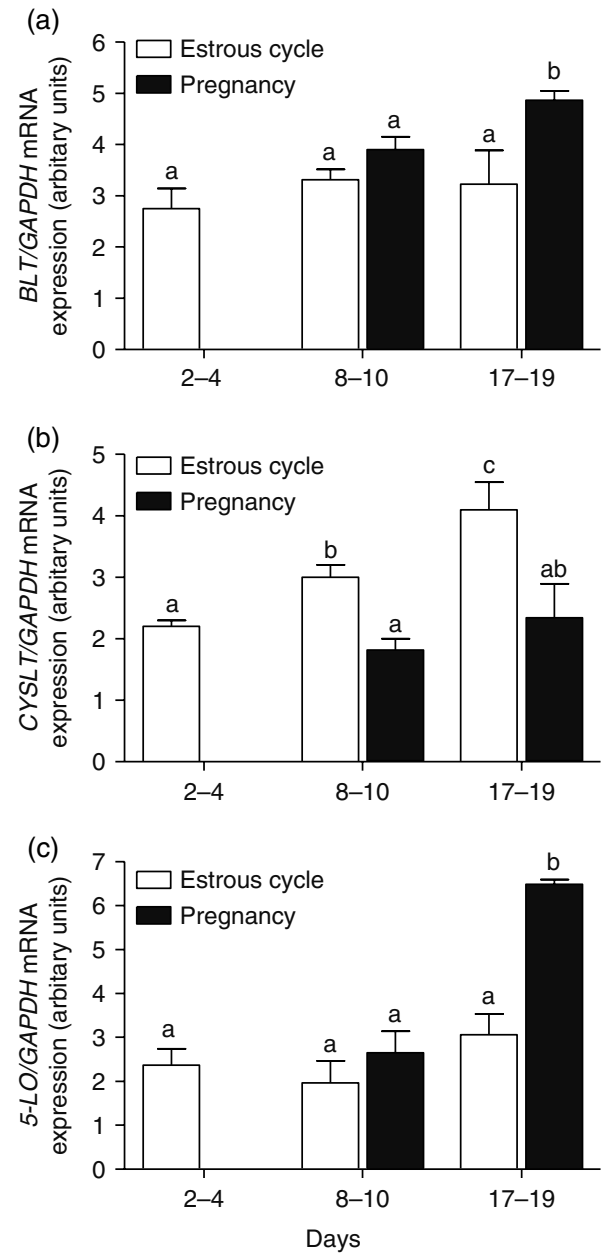

Figure 1 Pattern of expression of (a) BLT/LTRI, (b) CYSLT/LTRII, and (c) 5-LO mRNA on the selected days of the estrous cycle (white bars) and pregnancy (black bars) in the bovine $\mathrm{CL}$ tissue. Data are expressed as arbitrary units of respective mRNA/GAPDH mRNA. Different letters $(\mathrm{a}, \mathrm{b}$, and $\mathrm{c})$ indicate statistical differences $(P<0.05)$ in the quantitative mRNA expression between groups of cyclic or pregnant animals and statistical differences in the quantitative mRNA expression between groups of animals on the same days of the estrous cycle and pregnancy, as determined by two-way ANOVA followed by Bonferroni's multiple comparison test. 

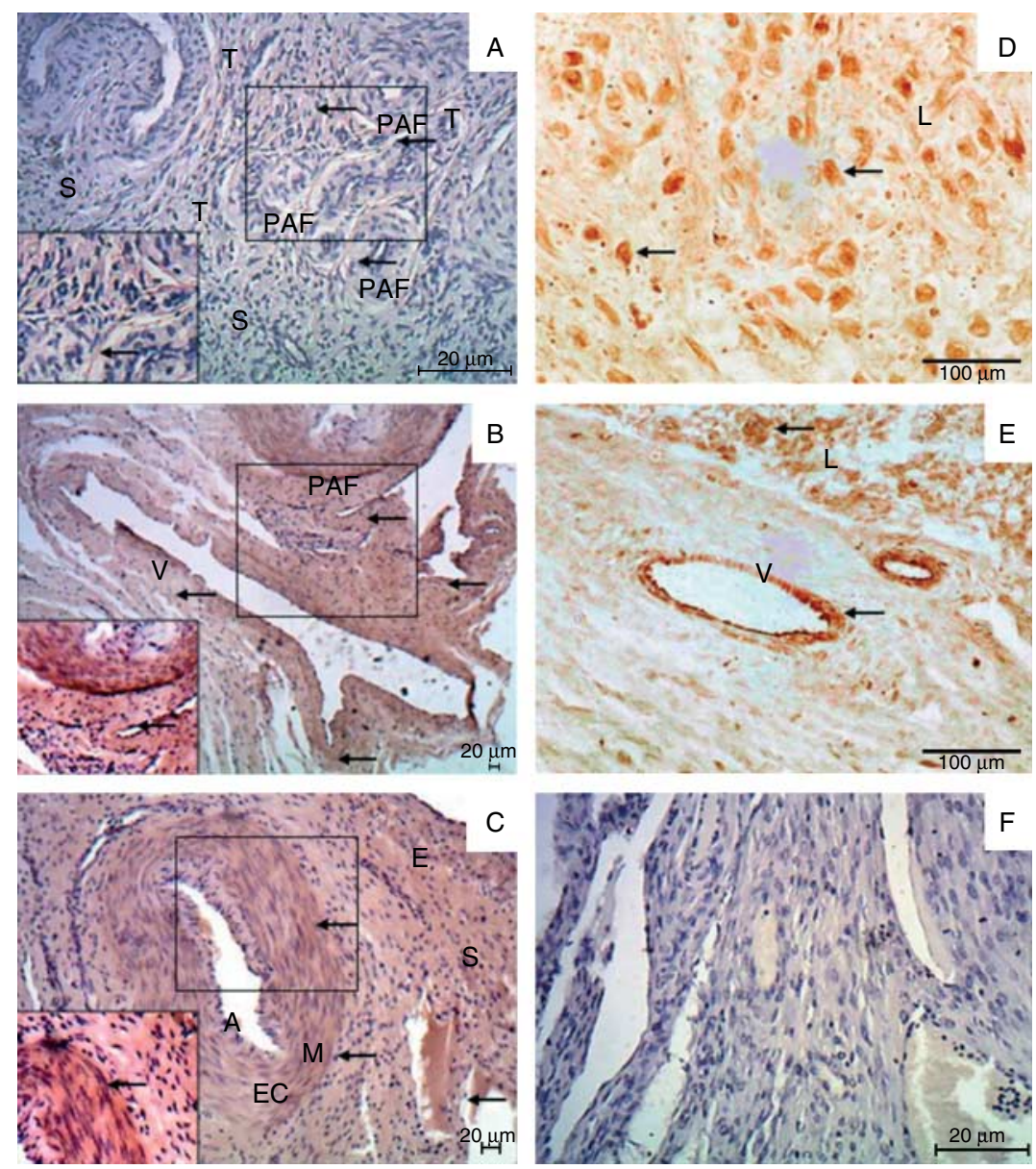

Figure 2 Representative immunohistochemical localization of BLT (A and D), CYSLT (B and E), and 5-LO $(\mathrm{C})$ in ovary on days $16-18$ of the estrous cycle, and a section incubated with rabbit IgG as a negative control (F). Bars: 20 and $100 \mu \mathrm{m}$. Arrows indicate the most intensive histochemical reactions. $\mathrm{T}$, theca cells; PAF, preantral follicle; $\mathrm{S}$, stromal cells; $\mathrm{V}$, vessel; A, aorta; EC, endothelial cells; E, epithelial cells; $M$, smooth muscle cells; $L$, luteal $C L$ cells. the level of $\mathrm{LTB}_{4}$ during the cycle remained unchanged $(P>0.05)$. During pregnancy, the level of $\mathrm{LTC}_{4}$ was stable $(P>0.05)$, whereas the level of $\mathrm{LTB}_{4}$ increased from day $8(P<0.05)$.

\section{Experiment 3: effects of $L T$ antagonists on $P_{4}$ and $P G s$ output and $C L$ lifespan in vivo}

Preliminary study: establishing the effective dose of $\mathrm{LTB}_{4}$ and $\mathrm{LTC}_{4}$ antagonists

$\mathrm{P}_{4}$ concentrations in blood plasma of control and experimental cows during the $24 \mathrm{~h}$ following LT infusion are shown in Fig. 5a and b. Azelastine at doses of 10 and $100 \mu \mathrm{g}$ did not influence $\mathrm{P}_{4}$ concentration in blood plasma in comparison with the control cows (Fig. 5a; $P>0.05)$. Azelastine at a dose of $250 \mu \mathrm{g}$ elevated secretion of $\mathrm{P}_{4}$ in the blood plasma compared with the control cows between 10 and $18 \mathrm{~h}$ following infusion $(P<0.05$; Fig. 5a). Although dapsone at a dose of $10 \mu \mathrm{g}$ temporarily increased the level of $\mathrm{P}_{4}$ at $2,3,8$, and $18 \mathrm{~h}$ of the experiment $(P<0.05$; Fig. 5b), a dose of $100 \mu \mathrm{g}$ did not influence secretion of $\mathrm{P}_{4}$ in the blood plasma compared with the control cows $(P>0.05$; Fig. 5b). Dapsone at a dose of $250 \mu$ inhibited $\mathrm{P}_{4}$ secretion from
$1 \mathrm{~h}$ after infusion $(P<0.05$; Fig. 5b). Additionally, in order to establish the effective dose of LT antagonists, the PG levels were measured (data not shown because no changes were observed following doses of 10 and $100 \mu \mathrm{g}$ for both LT antagonists).

\section{Effects of LT antagonists on $P_{4}$ and PG secretion, and on the lifespan of the $C L$ during the estrous cycle and early pregnancy}

The effects of azelastine and dapsone infusion $(250 \mu \mathrm{g}$ doses, as selected in the preliminary study) on the lifespan of the $C L$ during the a) estrous cycle and b) early pregnancy are shown in Fig. 6. Azelastine at a dose of $250 \mu \mathrm{g}$ was capable of prolonging the luteal phase of the estrous cycle for more than 30 days by increasing the lifespan of the $\mathrm{CL}(P<0.05$; Fig. 6a). On the contrary, dapsone at a dose of $250 \mu$ g shortened the length of the estrous cycle to $17 \pm 0.8$ days compared with saline-treated cows (day $21 \pm 0.9, P<0.05$; Fig. 6a). Azelastine did not influence $\mathrm{CL}$ function during early pregnancy ( $P>0.05$; Fig. 6b). Dapsone decreased the level of $\mathrm{P}_{4}$ from day 21 to day 30-32 (from 10.25 \pm 1.5 to $2.5 \pm 1.1 \mathrm{ng} / \mathrm{ml})$ of pregnancy $(P>0.05$; Fig. $6 \mathrm{~b})$ 

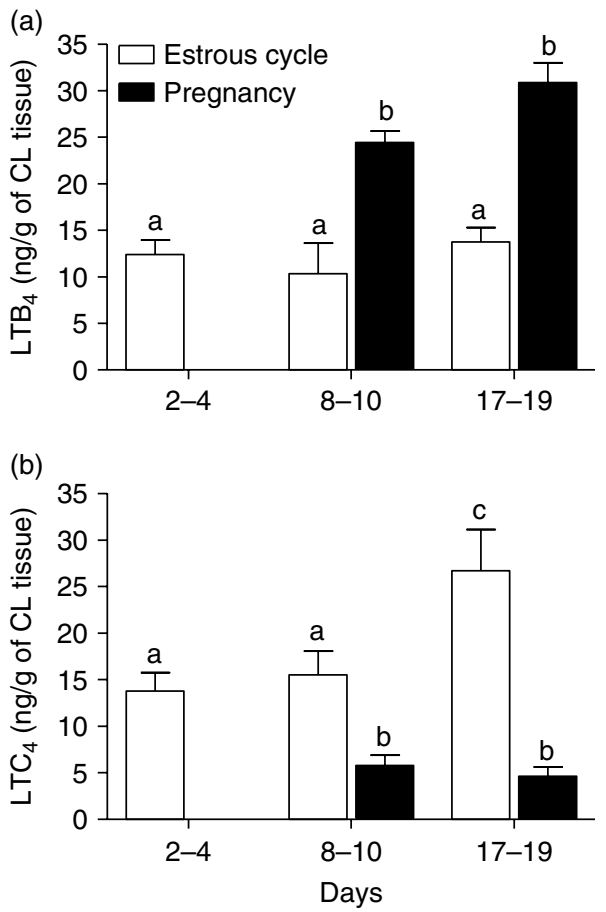

Figure 3 Concentrations of (a) $\mathrm{LTB}_{4}$ and (b) $\mathrm{LTC}_{4}$ in the CL tissue on the selected days of the estrous cycle (white bars) and pregnancy (black bars). Data are expressed as ng/g of the CL tissue. Different letters ( $a$ and b) indicate statistical differences $(P<0.05)$ in the LT concentration between groups of cyclic or pregnant animals, as determined by two-way ANOVA followed by Bonferroni's multiple comparison test.

and the absence of pregnancy was confirmed (by ultrasonography, USG) on day 36.

Figure 7 shows $\mathrm{P}_{4}, \mathrm{PGE}_{2}$, and PGFM concentrations in blood plasma of control and experimental cows after infusion of azelastine and dapsone $(250 \mu \mathrm{g})$ on day 16 of the estrous cycle (Fig. 7a-c) and pregnancy (Fig. 7d-f). During the estrous cycle, azelastine stimulated $\mathrm{P}_{4}$ output between 10 and $18 \mathrm{~h}$ after infusion $(P<0.05$; Fig. 7a). Dapsone inhibited $\mathrm{P}_{4}$ output from $1 \mathrm{~h}$ after infusion $(P<0.05$; Fig. 7a). During pregnancy, neither antagonist influenced secreted $\mathrm{P}_{4}$ in blood plasma $(P>0.05$; Fig. $7 \mathrm{~d})$.

During the estrous cycle, azelastine at a dose of $250 \mu \mathrm{g}$ stimulated $\mathrm{PGE}_{2}$ output at $0.5 \mathrm{~h}$ after infusion and from $10 \mathrm{~h}$ onward $(P<0.05$; Fig. $7 \mathrm{~b})$. However, dapsone at a dose of $250 \mu \mathrm{g}$ did not influence secreted $\mathrm{PGE}_{2}$ in blood plasma compared with the control cows and $\mathrm{PGE}_{2}$ output during the first $24 \mathrm{~h}$ of experiment in the cycle $\left(P>0.05\right.$; Fig. 7b). During pregnancy, the same $\mathrm{LTB}_{4}$ antagonist decreased $\mathrm{PGE}_{2}$ output and secretion at $1 \mathrm{~h}$ after infusion and from $4 \mathrm{~h}$ onward $(P<0.05$; Fig. $7 \mathrm{e})$, whereas azelastine did not alter $\mathrm{PGE}_{2}$ secretion in blood plasma compared with the control cows and $\mathrm{PGE}_{2}$ output during the $24 \mathrm{~h}$ after infusion (Fig. $7 \mathrm{e} ; P>0.05$ ).

Dapsone increased PGFM output in comparison to the control cows during the $24 \mathrm{~h}$ following infusion in the estrous cycle $(P<0.05 ;$ Fig. $7 \mathrm{C})$. On the other hand, azelastine did not influence PGFM concentration in blood plasma in comparison to the control cows (Fig. 7c; $P>0.05$ ). In pregnant cows, dapsone increased PGFM concentration in comparison to the control cows during the $24 \mathrm{~h}$ of the experiment $(P<0.05$; Fig. $7 \mathrm{f})$, whereas PGFM output was not affected by azelastine $(P>0.05$; Fig. 7f).

\section{Discussion}

In the present study, we found that LTs are produced and released in the bovine $\mathrm{CL}$, and they modulate the action of $\mathrm{P}_{4}$ and $\mathrm{PGs}$ in the bovine reproductive tract during the estrous cycle and early pregnancy. Our results revealed that LTs influence the lifespan of the CL during the estrous cycle and early pregnancy depending on the type of LT.

The highest levels of mRNA expression for LTRs and 5-LO in the CL tissue were observed on days 16-18 of both the estrous cycle and early pregnancy. We have previously described a similar pattern of mRNA expression of LTRs and 5-LO and production/secretion of LTs during the cycle in the two main cell populations of the bovine CL: steroidogenic and endothelial cells (Korzekwa et al. 2010a, 2010b). The highest mRNA expression levels for CYSLT and 5-LO were found on days 14-16 of the cycle in endothelial CL cells, whereas $B L T$ mRNA expression did not differ among cell types, which indicated that endothelial cells have the greatest potential for LT production among ovarian cells and are the main source of LTs in the bovine ovary (Korzekwa et al. 2010a, 2010b). Nevertheless, Chegini \& Rao (1988) showed numerous binding sites for LTC $_{4}$ in steroidogenic $\mathrm{CL}$ cells between 1.5 and 3 months of pregnancy in cattle. Immunostaining for LTRs and 5-LO showed that they were localized to ovarian vessels and luteal cells of the CL but also in ovarian follicles, which suggests a role for LTs in granulosa cells. According to the hypothesis of Brännström \& Enskog (2002), immune

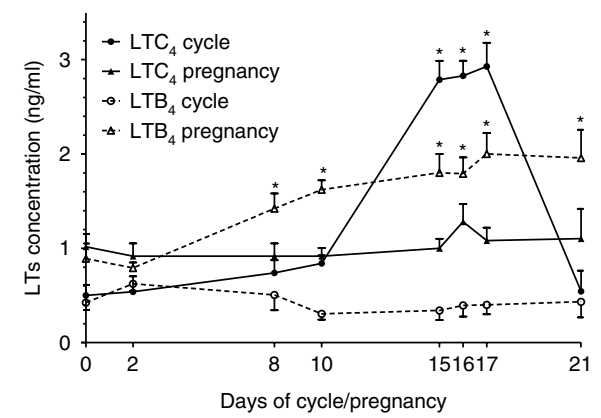

Figure 4 Profiles of $\mathrm{LTB}_{4}$ and $\mathrm{C}_{4}$ levels in peripheral blood plasma of cows collected on selected days of the cycle/pregnancy. Asterisks indicate statistical differences $(P<0.05)$ between $\mathrm{LTB}_{4}$ - and $\mathrm{LTC}_{4}$ treated groups at the same time of the experiment, as determined by one-way ANOVA followed by repeated measurement ANOVA tests followed by Bonferroni's multiple comparison test. 

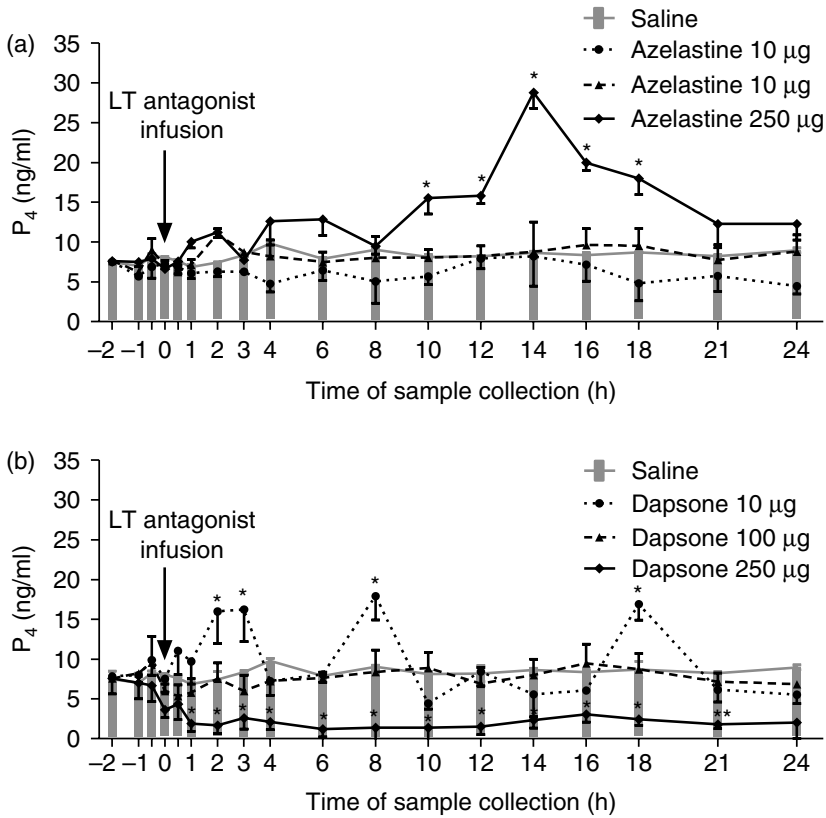

Figure 5 Concentrations of progesterone in peripheral blood plasma of cows infused with saline (gray bars) and various doses of the LT antagonists (a) azelastine and (b) dapsone. All reagents were infused into the aorta abdominalis. Asterisks indicate statistical differences $(P<0.05)$ between control and treated groups in the same time of collection, as determined by repeated measurement ANOVA tests followed by Bonferroni's multiple comparison test.

cells (macrophages, monocytes, and leukocytes) infiltrate the ovary and secrete cytokines during the ovulation. Cytokines affect nonsteroidogenic ovarian cells, causing the production/secretion of ovulation mediators, such as metabolites of arachidonic acid, i.e. PGs and LTs. Thus, LTs acting as autocrine or paracrine factors within the bovine CL may be involved not only in processes connected with vasculature, but also with steroidogenic and granulosa cell functions (Korzekwa et al. 2010a, 2010b).

Our data indicate that endogenous LTC $_{4}$ inhibits $\mathrm{P}_{4}$ secretion in the estrous cycle, since azelastine elevated $\mathrm{P}_{4}$ output. On the contrary, endogenous $\mathrm{LTB}_{4}$ action enhances $\mathrm{P}_{4}$ secretion, since dapsone inhibited $\mathrm{P}_{4}$ output in the estrous cycle. Nevertheless, the role of LTs in early pregnancy seems to be directly connected with PGs because blockade of endogenous LTs by both inhibitors had no effect on changes in $\mathrm{P}_{4}$ levels during the $24 \mathrm{~h}$ after infusion. Although LTs affected the CL lifespan in early pregnancy, the effect of LT action required a longer time after blockade of endogenous LTs by injection of LT antagonists. It is obvious that some factors mediate the action of PGs (Niswender et al. 2000). LTs of ovarian and/or uterine origin are suggested to be one of these mediators. It would be interesting to know whether LTs directly influence $\mathrm{P}_{4}$ production/ secretion in the $\mathrm{CL}$, both during the estrous cycle and in the process of embryo implantation during early pregnancy. Nevertheless, based on these in vivo results we are not able to fully understand the molecular interactions between LTs and $P_{4}$. Recent studies have shown that hydroxysteroid (11- $\beta$ ) dehydrogenase 1 (HSD11B1) action is dependent on PGs and $\mathrm{P}_{4}$ in the period of embryo implantation in cattle (Simmons et al. 2010). Further studies are needed to determine whether LTs affect the expression of HSD11B1. We showed that the role of LTs in the estrous cycle is strictly type dependent, since $\mathrm{LTC}_{4}$ inhibited $\mathrm{P}_{4}$ action, whereas $\mathrm{LTB}_{4}$ promoted $\mathrm{P}_{4}$ action in the bovine reproductive tract in vivo. In addition, LT levels measured in plasma during the estrous cycle and early pregnancy confirmed the specification of endogenous LTs dependently on its type in the reproductive tract. The $\mathrm{LTB}_{4}$ level was elevated during early pregnancy, whereas the $\mathrm{LTC}_{4}$ level was highest on days 15-17 in plasma and days 16-18 in the CL tissue during the estrous cycle. The levels of both PGs changed after infusion of LTs, both in the estrous cycle and in early pregnancy during the $24 \mathrm{~h}$ of the experiment. The $\mathrm{LTC}_{4}$ antagonist elevated $\mathrm{PGE}_{2}$ output in the estrous cycle, whereas $\mathrm{LTB}_{4}$ antagonist elevated PGFM output both in the cycle and pregnancy. An in vitro study carried out on steroidogenic and endothelial bovine CL cells on days $14-16$ of the cycle showed that LTs increased secretion of $\mathrm{PGE}_{2}$ as well as $\mathrm{PGF}_{2 \alpha}$ (Korzekwa et al. 2010b). Moreover, it is likely that the effect of $\mathrm{LT}$ secretion on steroidogenesis in the bovine $\mathrm{CL}$ is indirect and is mediated/supported by PGs and/or
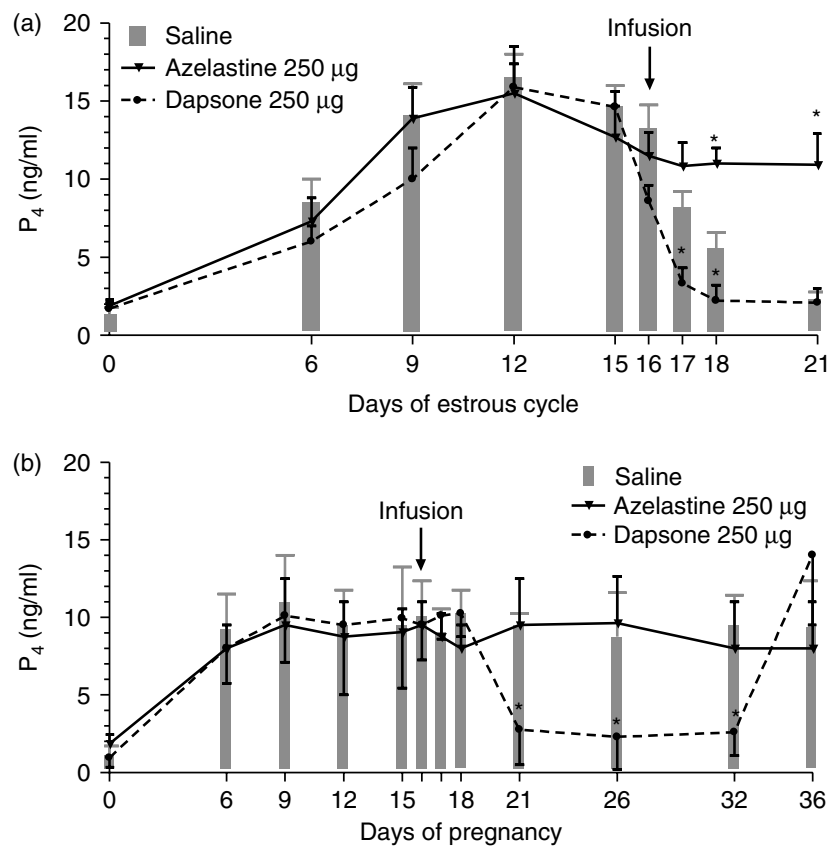

Figure 6 Progesterone levels in peripheral blood plasma of cows during (a) the estrous cycle and (b) early pregnancy after infusion of saline (gray bars), $250 \mu \mathrm{g}$ azelastine (line), or $250 \mu \mathrm{g}$ dapsone (dotted line). All reagents were infused into the aorta abdominalis. Asterisks indicate statistical differences $(P<0.05)$ between control and treated groups in the same time of experiment, as determined by repeated measurement ANOVA tests followed by Bonferroni's multiple comparison test. 
(a)

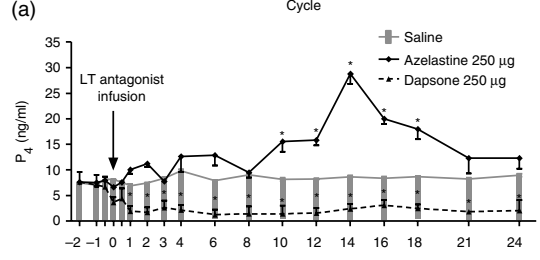

(b)

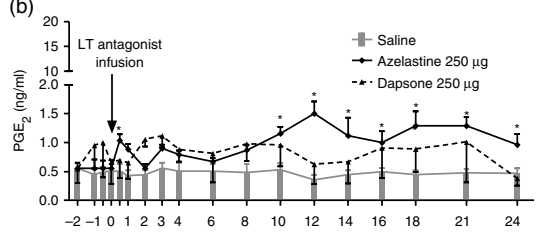

(c)

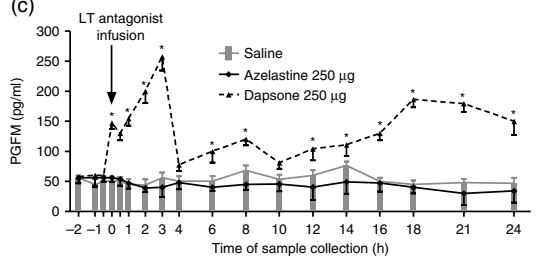

(d)
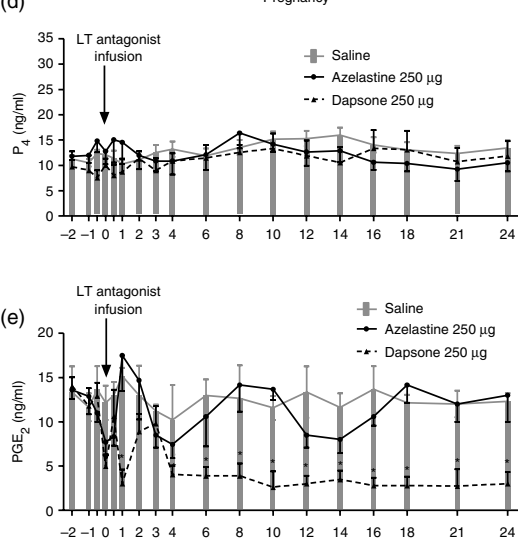

(f)

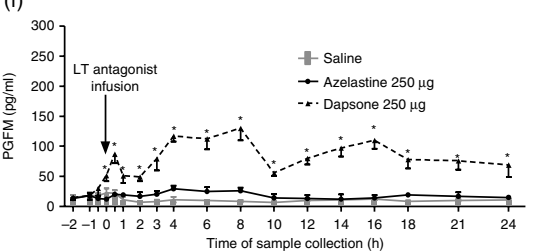

Figure 7 Concentrations of ( $\mathrm{a}$ and $\mathrm{d}$ ) progesterone, (b and e) prostaglandin $E_{2}$, and ( $c$ and $f$ ) 13,14-dihydro, 15-keto-PGF $2 \alpha$ in peripheral blood plasma of cows infused with saline (gray bars), $250 \mu \mathrm{g}$ azelastine (line), or $250 \mu \mathrm{g}$ dapsone (dotted line) on day 16 of the estrous cycle and early pregnancy. All reagents were infused into the aorta abdominalis. Asterisks indicate statistical differences $(P<0.05)$ between control and treated groups in the same time of experiment, as determined by repeated measurement ANOVA tests followed by Bonferroni's multiple comparison test. cytokines during the estrous cycle. Based on the results, we postulate that LT function in early pregnancy is rather directly connected with the implantation and development of the embryo, and at least with the action of PGs. The results obtained showed the opposing action of the endogenous $\mathrm{LTs}_{\mathrm{s}} \mathrm{LTB}_{4}$ and $\mathrm{C}_{4}$, in the bovine reproductive tract, because the LT antagonists used blocked LT action. Such a contrary action of LTs may be the consequence of other factors that are involved in transcriptional and translational modifications of LTs, and may influence the role of LTs in reproductive processes (Murphy \& Gijón 2007, Wittwer \& Hersberger 2007). Therefore, further studies are needed to determine the role of LTs in the reproductive tract.

Our results showed that $\mathrm{LTB}_{4}$, not $\mathrm{LTC}_{4}$, is involved in early pregnancy in cattle because $\mathrm{LTB}_{4}$ receptor mRNA expression and levels in the $C L$ tissue were higher in pregnancy than in the estrous cycle. In particular, $\mathrm{LTB}_{4}$ may interact with or mediate $\mathrm{PGE}_{2}$ and/or IFNT in process of embryo implantation and modulate the action of $\mathrm{PGE}_{2}$, which plays a pivotal role in early pregnancy (Weems et al. 1997). Indeed, a previous study has shown that the highest level of $\mathrm{LTA}_{4}$ hydrolase gene expression (which converts $\mathrm{LTA}_{4}$ to $\mathrm{LTB}_{4}$ and $\mathrm{LTC}_{4}$ ) was observed in human $C L$ cells at the mid-luteal stage and during pregnancy (Hattori et al. 1998). A high concentration of $\mathrm{LTB}_{4}$ in human fetal membranes was shown by Ticconi et al. (1998) and $\mathrm{LTB}_{4}$ enhanced human placental trophoblast cell function (Sato et al. 2008).

The data obtained in the current study strengthen the new concept that LTs are auto- and/or paracrine factors regulating reproductive processes in the $C L$ during the estrous cycle and early pregnancy. The mechanisms controlling development, functionality, and regression of the bovine $\mathrm{CL}$ involve many factors produced both inside and outside the CL (Niswender et al. 2000). We have demonstrated the production and secretion of LTs in the CL tissue and their localization in the ovary, and the influence of LTs on PG function during the estrous cycle and early pregnancy. Thus, $\mathrm{LTB}_{4}$ is luteotropic during the estrous cycle and supports early pregnancy, whereas $\mathrm{LTC}_{4}$ is luteolytic and its action is not desirable in early pregnancy.

\section{Materials and Methods}

All procedures were approved by the Local Animal Care and Use Committee, Olsztyn, Poland (agreement no. 58/2005/N).

A total of 84 healthy Holstein/Polish Black and White (75/25\% respectively) cows (3 or 4 lactation) were used for the collection of the ovaries with $\mathrm{CL}$ in experiment 1 , monitoring of the LT level in experiment 2, and checking the effects of LT antagonists on hormone output and CL lifespan in experiment 3. The animals were eliminated by the owners (Experimental Animal Farm of Polish Academy of Sciences in Baranowo and Agriculture Farm in Cieszymowo, Poland) from the dairy herds because of their lower milk production (years 2007-2009). The estrus of the cows was synchronized using two 5 mg PGF $2 \alpha$ analog (dinoprost, Dinolytic; UpjohnPharmacia N V S A) i.m. injections with an 11-day interval, as recommended by the vendor. The development of follicles and changes in $\mathrm{CL}$ structure during the estrous cycle were monitored by a veterinarian via per rectum USG examination using a Draminski Animalprofi Scanner (Draminski Electronics in Agriculture, Olsztyn, Poland) and confirmed by observing signs of estrus (i.e. vaginal mucus and standing behavior). The onset of estrus was taken as day 0 of the estrous cycle. Only the cows with signs of estrus were chosen for the study. 


\section{Experimental procedure}

Experiment 1: LT mRNA expression and production in the bovine $C L$ tissue and localization in the ovary during the estrous cycle and in early pregnancy

The aim of the experiment was to compare whether there are changes in LT production in the bovine CL during the estrous cycle and early pregnancy.

Bovine ovaries $(n=20)$ were obtained from cows divided into two groups: pregnant and cyclic animals. The animals allocated to the pregnant group underwent artificial insemination with semen from the same bull. Ovarian tissue was obtained at a local slaughterhouse (Zaklady Miesne 'Warmia', Biskupiec, Poland) within 20 min of exsanguination and was transported on ice to the laboratory within $40 \mathrm{~min}$. Estimation of the stages of the estrous cycle/pregnancy was monitored as mentioned (the reproductive history of all animals was known) and confirmed by macroscopic observation of the ovaries and uterus after slaughter (Miyamoto et al. 2000). Pregnancy was confirmed by flushing the uterus for embryo collection (Woclawek-Potocka et al. 2009).

Corpora lutea samples were collected on days 2-4 $(n=4)$, $8-10(n=4)$, and $16-18(n=4)$ of the estrous cycle and days $8-10(n=4)$ and $16-18(n=4)$ of pregnancy. The days of the estrous cycle for evaluation of $\mathrm{CL}$ functionality were additionally confirmed by measurement of $\mathrm{P}_{4}$ concentration in the peripheral blood. Pregnancy was confirmed as described previously (Woclawek-Potocka et al. 2009).

mRNA expression was quantitatively measured by real-time RT-PCR for 5-LO and $\mathrm{LTB}_{4}$ and $\mathrm{LTC}_{4}$ receptors (BLT and CYSLT respectively) as described previously (Korzekwa et al. 2010a). Concentrations of $\mathrm{P}_{4}$ (control of $\mathrm{CL}$ stage, data not shown), $\mathrm{LTB}_{4}$, and $\mathrm{LTC}_{4}$ were measured by enzyme immunoassay (EIA) in the CL tissues after extraction according to Korzekwa et al. (2008a). Immunohistochemistry was conducted in ovarian tissue for BLT, CYSLT, and 5-LO for observation of tissue compartments where LTs are produced.

Experiment 2: $\mathrm{LTB}_{4}$ and $\mathrm{C}_{4}$ concentrations in the blood during the estrous cycle and early pregnancy

The aim of the experiment was to follow and compare the changes in LTs concentration during the estrous cycle and early pregnancy. Peripheral blood samples were collected into tubes with $5 \mu \mathrm{l}$ EDTA and $1 \%$ aspirin solution $(\mathrm{pH} 7.3)$ from the jugular vein by syringe with needle on days $0,2,8,10,15,16$, 17 , and 21 of the estrous cycle or pregnancy. Blood plasma was separated by centrifugation $\left(2000 \mathrm{~g}\right.$; $10 \mathrm{~min}$ at $\left.4{ }^{\circ} \mathrm{C}\right)$ and stored at $-20^{\circ} \mathrm{C}$ until $\mathrm{P}_{4}, \mathrm{LTB}_{4}$, and $\mathrm{LTC}_{4}$ determinations were made $(n=12)$.

Experiment 3: effects of $L T$ antagonists on $\mathrm{P}_{4}$ and $P G$ output and CL lifespan in vivo

LT antagonists were used to test the hypothesis that LTs differentially affect the CL $(n=52)$ function and lifespan during the estrous cycle and early pregnancy.

Preliminary study: establishing the effective dose of $L T B_{4}$ and $L T C_{4}$ antagonists. On day 15 of the subsequent estrous cycle, catheters were inserted into the aorta abdominalis through the coccygeal artery of the cows for infusion of either saline $(n=4)$ or $\mathrm{LTB}_{4}$ and $\mathrm{C}_{4}$ antagonists. A second catheter was inserted into the jugular vein for frequent collection of blood samples (Skarzynski et al. 2003a).

The LT antagonists were infused into the aorta abdominalis on day 16 of the estrous cycle: azelastine (an antagonist of $\mathrm{LTC}_{4}$; azelastine hydrochloride, LKT-A9818-M100; Alexis Biochemicals, Lausen, Switzerland) and dapsone (an antagonist of $\mathrm{LTB}_{4} ; 4$, 4'-diaminodiphenyl sulfone, LKT- ALX-270-090; Alexis Biochemicals) each in three doses: 10, 100, and $250 \mu \mathrm{g}$ ( $n=4$ for each dose of LT antagonist) in $20 \mathrm{ml}$ of saline. Peripheral blood samples were collected from the jugular vein before and for $24 \mathrm{~h}$ after treatment $(18$ times, beginning $2 \mathrm{~h}$ before the infusions as follows: $-2,-1,-0.5,0,0.5,1,2,3$, $4,6,8,10,12,14,16,18,21$, and 24 h). After day 16 of the estrous cycle, blood was collected once daily until day 22 $(n=28)$. The concentrations of $\mathrm{P}_{4}$ and PGs $\left(\mathrm{PGE}_{2}\right.$ and PGFM; data not shown) in plasma samples were measured. Standing behavior was checked every $12 \mathrm{~h}$ after treatment to confirm the onset of estrus.

Effects of LT antagonists on $\mathrm{P}_{4}$ and PG secretion and CL lifespan during the estrous cycle and early pregnancy

To determine the effects of LT antagonists on CL lifespan and $\mathrm{P}_{4}$ levels during pregnancy, peripheral blood samples were collected from the jugular vein on days $0,6,9,12,15,16$, 17,18 , and 21 of the estrous cycle and days $0,6,9,12,15,16$, $17,18,21,26,32$, and 36 of the pregnancy (embryo presence/absence was confirmed on day 32 of pregnancy by USG). The concentrations of $\mathrm{P}_{4}$ in the plasma samples were measured after centrifugation, as in experiment 2 .

To check the effect of blockade of endogenous LT actions on $\mathrm{CL}$ function during the estrous cycle and early pregnancy, saline $(n=8)$ and $250 \mu \mathrm{g}$ (the dose selected in the preliminary study) dapsone $(n=8)$ or azelastine $(n=8)$ were infused into the aorta abdominalis on day 16 of the estrous cycle $(n=24)$ or pregnancy ( $n=24$, including 12 animals used from the preliminary study) according to the experimental design from the preliminary study. Peripheral blood samples were collected from the jugular vein before and for $24 \mathrm{~h}$ after infusion (18 times, beginning $2 \mathrm{~h}$ before the infusions). The concentrations of $\mathrm{P}_{4}, \mathrm{PGE}_{2}$, and PGFM in the plasma samples were measured.

\section{Immunocytochemistry for $L_{T B}$ receptor (BLT), $L T C_{4}$ receptor (CYSLT), and 5-LO protein}

Cross sections of ovarian tissue samples were fixed in $4 \%$ paraformaldehyde in $0.1 \mathrm{M}$ PBS $(\mathrm{pH}=7.4)$, washed in $0.1 \mathrm{M}$ PBS, and cryoprotected in $18 \%$ sucrose. Immunostaining was carried out on consecutive sections. Afterwards, $10 \mu \mathrm{m}$ cryostat sections were stained for specific LT receptors and 5-LO. To block endogenous peroxidase, the sections were treated with hydrogen peroxide in methanol and washed in $0.1 \mathrm{M}$ PBS. Then they were blocked with $10 \%$ normal goat serum for $1 \mathrm{~h}$ at room temperature, incubated overnight at room temperature with primary rabbit $\mathrm{MAB}$ raised against $\mathrm{LTB}_{4}$ receptor (GTX71293; GeneTex Inc., Irvine, CA, USA), LTC 4 receptor 
(APO6853PU-N; Acris GmbH, Herford, Germany), and 5-LO (160402 Cayman; Cayman Chemical Co., Ann Arbor, MI, USA), all diluted at 1:100, washed in PBS, incubated for $1 \mathrm{~h}$ at room temperature with 1:200 biotynylated anti-rabbit antibody (AK-5001 Vectastain ABC kit; Vector Laboratories, Peterborough, UK), washed, incubated for 45 min with $A B C$ reagent in PBS, and washed again. Proteins were visualized by incubating

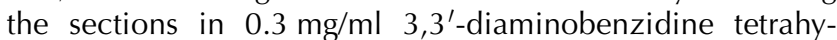
drochloride (Sigma Chemical Co. Ltd) in $0.01 \%$ hydrogen peroxide in Tris-buffered saline $(\mathrm{pH}=7.2)$ for $2-3 \mathrm{~min}$. Finally, sections were dehydrated and cover-slipped with DPX mounting medium (Park Scientific Ltd, Northampton, UK). To test the specificity of immunohistochemical staining, two types of controls were performed: i) the primary antibody was omitted during the immunostaining procedure; and ii) the primary antibody was substituted with nonspecific IgG. The observations and photographs were made using a light microscope (Nikon FXA, Tokyo, Japan). Classification of ovarian follicles was described according to Rodgers \& Irving-Rodgers (2010).

\section{Total RNA isolation}

Total RNA was extracted from ovaries using Trizol reagent according to the manufacturer's instructions. One microgram of each sample of total RNA was reverse transcribed using the SuperScript First-Strand Synthesis System for RT-PCR (11904-018; Invitrogen), as described in the supplier's protocol.

\section{Real-time PCR quantification}

Quantitative fluorescence real-time PCR was performed using the Applied Biosystems 7300 System (Applied Biosystems, Foster City, CA, USA) with an SYBR Green PCR master mix (4367659 Power SYBR Green PCR Master Mix; Applied Biosystems) following the manufacturer's instructions. Realtime PCR $(25 \mu \mathrm{l})$ included $12.5 \mu \mathrm{l}$ SYBR Green PCR Master Mix, $0.5 \mu \mathrm{M}$ each of sense and antisense primers, and reversetranscribed cDNA ( $1 \mu \mathrm{l}$ cDNA). The primers for 5-LO, BLT, and CYSLT mRNA expression were as detailed in a previous paper (Korzekwa et al. 2010a). For quantification, standard curves consisting of serial dilutions of the appropriate purified cDNA were plotted. Amplification was preceded by an initial denaturation step $\left(15 \mathrm{~min}\right.$ at $\left.95^{\circ} \mathrm{C}\right)$. The PCR programs for each gene were performed as follows: 40 cycles of denaturation $\left(15 \mathrm{~s}\right.$ at $\left.95^{\circ} \mathrm{C}\right)$, annealing $\left(30 \mathrm{~s}\right.$ at $\left.56^{\circ} \mathrm{C}\right)$, and elongation $\left(60 \mathrm{~s}\right.$ at $\left.72^{\circ} \mathrm{C}\right)$. After PCR, melting curves were acquired by stepwise increases at a temperature of $50-95{ }^{\circ} \mathrm{C}$ to ensure that a single product was amplified in the reaction. Control reactions in the absence of RT were performed to test for genomic DNA contamination. The specificity of the PCR products for examined genes was confirmed by gel electrophoresis and sequencing. The sequence homology obtained in the experiment was 99\%. Dissociation curve analysis was performed after each real-time experiment to confirm the presence of only one product and the absence of the formation of primer dimers. Data were normalized to a calibrator sample using the $\Delta \Delta C_{\mathrm{t}}$ method. Samples were run in triplicate, data are shown as the average fold increase, with S.E.M., and were expressed relative to GAPDH as a housekeeping gene, which was expressed at the same levels ( $C_{\mathrm{t}}$ values) for all examined genes and stages of the estrous cycle and pregnancy.

\section{Extraction of hormones from the CL tissue}

LTs were extracted from the CL tissue according to the method described previously (Korzekwa et al. 2008a).

\section{Hormone determination}

Measurements of $\mathrm{P}_{4}$ and $\mathrm{PGE}_{2}$ in the $\mathrm{CL}$ tissue and plasma were performed using a direct EIA as described previously (Skarzynski et al. 2003a, 2003b, Korzekwa et al. 2004). Antiserum to $\mathrm{P}_{4}$ was donated by Dr S Okrasa (University of Warmia and Mazury, Olsztyn, Poland). The standard curve ranged from 0.39 to $100 \mathrm{ng} / \mathrm{ml}$ and the effective dose for $50 \%$ inhibition $\left(E_{50}\right)$ of the assay was $4.5 \mathrm{ng} / \mathrm{ml}$. The intra- and interassay coefficients of variation $(\mathrm{CV})$ values were 5.5 and $8.5 \%$ respectively. The $\mathrm{PGE}_{2}$ standard curve ranged from 0.07 to $20 \mathrm{ng} / \mathrm{ml}$ and the $\mathrm{ID}_{50}$ of the assay was $1.25 \mathrm{ng} / \mathrm{ml}$. The intraand interassay $\mathrm{CV}$ values averaged 6.9 and $9.7 \%$ respectively.

The concentrations of PGFM in the plasma samples were determined with a direct EIA, as described previously (Skarzynski et al. 2003a). The anti-PGFM serum (WS4468-5) was donated by Dr W J Silvia (University of Kentucky, Lexington, KY, USA). The PGFM standard curve was produced for PGFM concentrations ranging from 32.5 to $8000 \mathrm{pg} / \mathrm{ml}$ and the $\mathrm{ID}_{50}$ of the assay was $315 \mathrm{pg} / \mathrm{ml}$. The intra- and interassay CV values were on average 7.6 and $10.4 \%$ respectively.

The concentrations of $\mathrm{LTB}_{4}$ and $\mathrm{C}_{4}$ were determined in the culture media using commercially available EIA kits (520211, $\mathrm{LTC}_{4}$ EIA kit; 520111, LTB 4 EIA kit; Cayman Chemical Co.) according to Korzekwa et al. (2008b). The $\mathrm{LTB}_{4}$ standard curve ranged from 1.96 to $1000 \mathrm{pg} / \mathrm{ml}$, and the effective dose for $50 \%$ inhibition $\left(\mathrm{ID}_{50}\right.$ ) of the assay was $2.5 \mathrm{pg} / \mathrm{ml}$. The intra- and interassay $\mathrm{CV}$ values were on average 4.1 and $6.2 \%$ respectively. The $\mathrm{LTC}_{4}$ standard curve ranged from 0.98 to $500 \mathrm{pg} / \mathrm{ml}$ and the effective dose for $50 \%$ inhibition $\left(\mathrm{ID}_{50}\right)$ of the assay was $1.85 \mathrm{pg} / \mathrm{ml}$. The intra- and interassay CV values were on average 4.9 and $7.4 \%$ respectively.

\section{Statistical analysis}

In experiment 1, the determination of every measurement for each group was performed in triplicate. The statistical significance of differences in 5-LO, BLT, and CYSLT expression and the statistical significance of differences in hormone concentrations were analyzed by two-way ANOVA followed by Bonferroni's post hoc test (ANOVA; GraphPAD PRISM Version 4.00, San Diego, CA, USA), if the initial ANOVA was significant $(P<0.05)$. The intensity of the histochemical reactions was estimated by the measurement of optical density (0-450) using Olympus DP SOFT Software (Olympus, Warsaw, Poland). Three slides of each sample were stained and examined under a light microscope (Nikon Microphot FXA).

LT concentration and differences during the estrous cycle and in early pregnancy in experiments 2 and 3, as well the analyses of $\mathrm{P}_{4}, \mathrm{PGE}_{2}$, and PGFM in the plasma samples, 
collected before, during, and after administration of LT antagonists, were performed using a repeated measures design approach with treatments and the time of sample collection (hours, or days of the cycle or pregnancy) being fixed effects with all interactions included repeated measurement ANOVA tests followed by Bonferroni's multiple comparison test (GraphPAD PRISM Version 5.00). $P<0.05$ was considered significant.

\section{Declaration of interest}

The authors declare that there is no conflict of interest that could be perceived as prejudicing the impartiality of the research reported.

\section{Funding}

This research was supported by grants-in-aid for scientific research from the Polish Ministry of Scientific Research and Higher Education (2P06D 00430 and N N311 01 3837).

\section{Acknowledgements}

The authors are indebted to thank D V Przemyslaw Warmowski for assistance during in vivo experiment and USG examination, and Ewa Rewinska for assistance during in vivo experiment and EIA determinations in experiment 3. We thank Dr Stanislaw Okrasa of the Warmia and Mazury University in Olsztyn (Poland) for $\mathrm{P}_{4}$ antiserum, Dr W J Silvia (University of Kentucky, Lexington, KY, USA) for PGFM antiserum, and the firm Draminski (Olsztyn, Poland) for use of the USG scanner to monitor the phase of the estrous cycle in experimental cows. The authors also thank the heads of the animal farms, Mr Maciej Baurycza (Animal Farm of Cieszymowo) and Mr Henryk Jabłoński (Experimental Animal Farm of the Polish Academy of Sciences in Baranowo) for their excellent cooperation and for allowing us to use the animals for this study, and Mr Marek Domin, the owner of the slaughterhouse (Zaklady Miesne 'Warmia,' Biskupiec, Poland) for permitting collection of the material.

\section{References}

Arosh JA, Banu SK, Kimmins S, Chapdelaine P, Maclaren LA \& Fortier MA 2004 Effect of interferon- $\tau$ on prostaglandin biosynthesis, transport, and signaling at the time of maternal recognition of pregnancy in cattle: evidence of polycrine actions of prostaglandin $\mathrm{E}_{2}$. Endocrinology $\mathbf{1 4 5}$ 5280-5293. (doi:10.1210/en.2004-0587)

Bazer FW, Burghardt RC, Johnson GA, Spencer TE \& Wu G 2008 Interferons and progesterone for establishment and maintenance of pregnancy: interactions among novel cell signaling pathways. Reproductive Biology 8 179-211.

Blair RM, Saatman R, Liou SS, Fortune JE \& Hansel W 1997 Roles of leukotrienes in bovine corpus luteum regression: an in vivo microdialysis study. Proceedings of the Society for Experimental Biology and Medicine $21672-80$

Brännström M \& Enskog A 2002 Leukocyte networks and ovulation. Journal of Reproductive Immunology 57 47-60. (doi:10.1016/S01650378(02)00009-8)
Chegini N \& Rao CV 1988 The presence of leukotriene C4-binding sites in bovine corpora lutea of pregnancy. Biology of Reproduction 39 929-935. (doi:10.1095/biolreprod39.4.929)

Eley RM, Thatcher WW, Bazer FW \& Fields MJ 1983 Steroid metabolism by the bovine uterine endometrium and conceptus. Biology of Reproduction 28 804-816. (doi:10.1095/biolreprod28.4.804)

Hattori N, Fujiwara H, Maeda M, Yoshioka S, Higuchi T, Mori T, Ohishi N, Minami M, Fujii S \& Ueda M 1998 Human large luteal cells in the menstrual cycle and early pregnancy express leukotriene A hydrolase. Molecular Human Reproduction 4 803-810. (doi:10.1093/molehr/4.8.803)

Izumi T, Yokomizo T, Obinata H, Ogasawara H \& Shimizu T 2002 Leukotriene receptors: classification, gene expression, and signal transduction. Journal of Biochemistry 132 1-6.

Jones TR \& Rodger IW 1999 Role of leukotrienes and leukotriene receptor antagonists in asthma. Pulmonary Pharmacology 12 107-110. (doi:10.1006/ pupt.1999.0188)

Korzekwa A, Jaroszewski J, Bogacki M, Deptula KM, Maslanka TS, Acosta TJ, Okuda K \& Skarzynski DJ 2004 Effects of prostaglandin F $(2 \alpha)$ and nitric oxide on the secretory function of bovine luteal cells. Journal of Reproduction and Development 50 411-417. (doi:10.1262/jrd.50.411)

Korzekwa A, Murakami S, Wocławek-Potocka I, Bah MM, Okuda K \& Skarzynski DJ 2008a The influence of tumor necrosis factor $\alpha$ (TNF) on the secretory function of bovine corpus luteum: TNF and its receptors expression during the estrous cycle. Reproductive Biology 8 245-262.

Korzekwa AJ, Jaroszewski JJ, Woclawek-Potocka I, Bah MM \& Skarzynski DJ $2008 b$ Luteolytic effect of prostaglandin $\mathrm{F}_{2 \alpha}$ on bovine corpus luteum depends on cell composition and contact. Reproduction in Domestic Animals 43 464-472. (doi:10.1111/j.1439-0531.2007.00936.x)

Korzekwa A, Lukasik K \& Skarzynski DJ 2010a Leukotrienes are auto-/paracrine factors in the bovine corpus luteum: an in vitro study. Reproduction in Domestic Animals [in press]. (doi:10.1111/j.14390531.2009.01500.x)

Korzekwa A, Acosta TJ, Miklewicz M, Lee SH \& Skarzynski DJ 2010b What is the target for leukotrienes action within bovine ovary? Reproduction in Domestic Animals [in press].

Kotwica J, Skarzynski D, Mlynarczuk J \& Rekawiecki R 2003 Role of prostaglandin $E_{2}$ in basal and noradrenaline-induced progesterone secretion by the bovine corpus luteum. Prostaglandins \& Other Lipid Mediators 70 351-359. (doi:10.1016/S0090-6980(02)00149-1)

Lewis GS, Thatcher WW, Bazer FW \& Curl JS 1982 Metabolism of arachidonic acid in vitro by bovine blastocysts and endometrium. Biology of Reproduction 27 431-439. (doi:10.1095/biolreprod27.2.431)

McCracken JA, Custer EE \& Lamsa JC 1999 Luteolysis: a neuroendocrinemediated event. Physiological Reviews 79 263-323.

Milvae RA, Alila HW \& Hansel W 1986 Involvement of lipoxygenase products of arachidonic acid metabolism in bovine luteal function. Biology of Reproduction 35 1210-1215. (doi:10.1095/biolreprod35.5. 1210)

Miyamoto Y, Skarzynski DJ \& Okuda K 2000 Is tumor necrosis factor- $\alpha$ a trigger for the initiation of prostaglandyn $F_{2 \alpha}$ releasse at luteolysis in cattle? Biology of Reproduction 62 1109-1115. (doi:10.1095/biolreprod62.5.1109)

Murphy RC \& Gijón MA 2007 Biosynthesis and metabolism of leukotrienes. Biochemical Journal 405 379-395. (doi:10.1042/BJ20070289)

Niswender GD, Juengel JL, Silva PJ, Rollyson MK \& McIntush EW 2000 Mechanisms controlling the function and life span of the corpus luteum. Physiological Reviews 80 1-29.

Rodgers RJ \& Irving-Rodgers HF 2010 Morphological classification of bovine ovarian follicles. Reproduction 139 309-318. (doi:10.1530/REP09-0177)

Samuelsson B 2000 The discovery of the leukotrienes. American Journal of Respiratory and Critical Care Medicine 161 2-6.

Sato K, Chisaka H, Okamura K \& Challis JRG 2008 Effect of the interaction between lipoxygenase pathway and progesterone on the regulation of hydroxysteroid $11-\beta$ dehydrogenase 2 in cultured human term placental trophoblasts. Biology of Reproduction 78 514-520. (doi:10.1095/ biolreprod.107.064717)

Simmons RM, Satterfield S, Welsh TH Jr, Bazer FW \& Spenser TE 2010 HSD11B1, HSD11B2, PTGS2, and NR3C1 expression in the peri-implantation ovine uterus: effects of pregnancy, progesterone, and interferon tau. Biology of Reproduction 82 35-43. (doi:10.1095/biolreprod.109.079608) 
Skarzynski DJ, Jaroszewski JJ, Bah MM, Deptuła KM, Barszczewska B, Gawronska B \& Hansel W 2003a Administration of a nitric oxide synthase inhibitor counteracts prostaglandin $\mathrm{F}_{2 \alpha}$-induced luteolysis in cattle. Biology of Reproduction 68 1674-1681. (doi:10.1095/biolreprod. 102.008573)

Skarzynski DJ, Bah MM, Deptula KM, Woclawek-Potocka I, Korzekwa A, Shibaya M, Pilawski W \& Okuda K $2003 b$ Roles of tumor necrosis factor$\alpha$ of the estrous cycle in cattle: an in vivo study. Biology of Reproduction 69 1907-1913. (doi:10.1095/biolreprod.103.016212)

Spencer TE, Johnson GA, Bazer FW, Burghardt RC \& Palmarini M 2007 Pregnancy recognition and conceptus implantation in domestic ruminants: roles of progesterone, interferons and endogenous retroviruses. Reproduction, Fertility, and Development 19 65-78. (doi:10.1071/RD06102)

Tager AM \& Luster AD 2003 BLT1 and BLT2: the leukotriene B4 receptors. Prostaglandins, Leukotrienes, and Essential Fatty Acids 69 123-134. (doi:10.1016/S0952-3278(03)00073-5)

Thatcher WW, Bartol FF, Knickerbocker JJ, Curl JS, Wolfenson D, Bazer FW \& Roberts RM 1984 Maternal recognition of pregnancy in cattle. Journal of Dairy Science 67 2797-2811. (doi:10.3168/jds.S00220302(84)81636-7)

Thatcher WW, Guzeloglu A, Mattos R, Binelli M, Hansen TR \& Pru JK 2001 Uterine-conceptus interactions and reproductive failure in cattle. Theriogenology 56 1435-1450. (doi:10.1016/S0093-691X(01)00645-8)

Ticconi C, Mauri A, Zicari A, Angeloni U, Loyola G \& Piccione E 1998 Interrelationships between oxytocin and eicosanoids in human fetal membranes at term gestation: which role for leukotriene $B_{4}$ ? Gynecological Endocrinology 12 129-134. (doi:10.3109/09513599 809024961)

Weems YS, Bridges PJ, Tanaka Y, Sasser RG, LeaMaster BR, Vincent DL \& Weems CW $1997 \mathrm{PGE}_{1}$ or $\mathrm{PGE}_{2}$ not LH regulates secretion of progesterone in vitro by the 88-90 day ovine corpus luteum of pregnancy. Prostaglandins 53 337-353. (doi:10.1016/0090-6980(97)00037-3)

Weems CW, Weems YS \& Randel RD 2006 Prostaglandins and reproduction in female farm animals. Veterinary Journal 171 206-228. (doi:10.1016/j.tvjl.2004.11.014)

Wittwer J \& Hersberger M 2007 The two faces of the 15-lipoxygenase in atherosclerosis. Prostaglandins, Leukotrienes, and Essential Fatty Acids 77 67-77. (doi:10.1016/j.plefa.2007.08.001)

Woclawek-Potocka I, Komiyama J, Saulnier-Blache JS, Brzezicka E, Bah MM, Okuda K \& Skarzynski DJ 2009 Lysophosphatic acid modulates prostaglandin secretion in the bovine uterus in vitro and in vivo. Reproduction 137 95-105. (doi:10.1530/REP-08-0209)

Received 30 April 2010

First decision 7 June 2010

Revised manuscript received 1 August 2010

Accepted 20 August 2010 